\title{
Editorial: Towards a New Agenda
}

The growth in the urban leisure market over the last decade has been headline news. The rise in multiplex cinemas and other urban entertainment venues has been the result of increasing demand for leisure 'products' consequent on rising real incomes. Throughout the developed world, leisure operators, supported by the property industry, have created venues to tap into the spending power of the affluent. But have they created an oversupply? With the slowdown of economic growth in many parts of the globe, the shortcomings of some schemes have been exposed and the failure, in financial terms, of many schemes has become a reality or inevitability. For example, recent reports by the specialist cinema research house, Dodona, ${ }^{1}$ point to worrying trends for those involved with multiplex developments both in the UK and elsewhere. They claim that, put simply, the problem is that the development process is so protracted that it is hard to react speedily to changes in the economic environment. Like a 'supertanker' it takes a long time to get developments off the ground and a long time to slow down the trend when the prospects weaken.

But is this analysis an excuse for the leisure development industry's failure to learn the lessons from other boom and bust scenarios that have plagued the property world over decades? Although economic analysis and projection many be an essentially inaccurate business, ${ }^{2}$ both the leisure and property industries are cyclical, a point amply demonstrated in this issue by Sonti and Rouse in their review and analysis of European hotel transactions. The level of growth that has been witnessed on the supply side could reasonably be expected to create operational difficulties in due time. The difficulty, of course, is that every developer anticipates that their scheme will have sufficient product differentiation to give lasting competitive advantage. Blatantly many have not succeeded in this. Kaufman, writing in Leisure Management, ${ }^{3}$ argues that many attractive developments fail due to poor planning, bad management, under-financing and 'racing ahead of the population's spending power'. The fundamentals of successful attractions development, she argues, include good financial planning, money for re-investment in recognition of the need to constantly 'refresh' the experience and value for money.

These messages are ones that are developed within many of the papers contained in this edition of the Journal. In the views of our contributors, the issues of funding, proper planning and good management are ones that must be designed into successful leisure schemes. Collectively, they point to many of the issues that the leisure property industry must now address. If the past has been 
about an emergent sector, now is the time that a more mature approach is called for that may need a more critical approach to the origination of schemes.

One of the difficulties facing any leisure analyst is in defining what is meant by leisure. Essentially, leisure is an abstract concept, but within its kernel is the notion of discretion. Whatever part of leisure is contemplated, be it tourism, entertainment or sport, leisure's relationship with property is about attracting people for an 'experience'. Swarbrooke points out in his article on the challenges of managing visitor attractions, that the leisure experience may be founded in many ways. It could be a specific man-made venue, such as a theme park or a heritage spin-off of a historic legacy (for example, in a city such as Prague or Bath) or it may relate to natural beauty (such as a national park). Whatever the fundamental essence of the attraction, he argues, there is a need to recognise the connectivity between that asset and the wider marketplace.

Behind this key challenge is the acceptance that the leisure pound is essentially discretionary. People have the ability to choose how - and where - they spend their money. If an oversupply of opportunities arises then the issue for leisure operators becomes one of management to ensure that their competitive advantage is both identified and marketed. It will not be enough, as Swarbrooke points out, simply to provide the attraction - there must be understanding of the true nature of the competition. This theme is taken up by Yeoman et al. who call for operators to develop more sophisticated models of forecasting in order to better protect the revenue stream.

The nature of competition within the leisure attractions market is not always obvious. With the growth of Internet usage, which widens knowledge of alternatives, the real competitor to a country cottage holiday in Devon may be the weekend break in Budapest and the MPC may be in competition with the DVD at home or the publicly funded 'edutainment' presented by a hands-on museum. This, of course, makes the task of predicting future spending trends even more difficult. Within the tourism sector, growth in the "last minute' decision making facilitated by Web bookings has meant that consumers do not need to be 'locked in' to their major leisure spending decisions, such as holidays, months in advance. Admittedly, there are some who like to take time to plan the annual escape over months, but the move to instant decision making is growing and it is very clear that tourism and leisure are not standalone businesses operating in clearly defined, or definable, markets.

As tourist attraction operators in the UK have found out this year to their very heavy cost, a crisis in agriculture has had an appalling knock-on effect on their profitability - and one that is receiving no compensation. At the current time, the UK government is struggling to come to terms with the estimated $£ 2 b n$ cost to the taxpayer of the foot-and-mouth epidemic without 
contemplating any compensation for consequential loss to the tourist industry. Yet tourism and leisure employs some 10 per cent of the UK workforce and has a far wider significance to the overall economic health of the country than does agriculture. There needs to be a deeper understanding of the inter-relationships - symbiotic or otherwise - of leisure spending and the wider economy and, indeed, the physical infrastructure.

Planning must play a crucial part in the future. Butter, writing in the UK context, calls on the leisure property industry to work with government to provide a more unified approach to the matter of leisure land use planning - something that has been very fragmented in the past. In this, Butter is echoing sentiments made by $\mathrm{McIntosh}^{4}$ who calls for new planning policy guidance. Evans and Shaw, too, see the need for greater integration, in this case between leisure planning and transportation in order to serve the cause of urban renewal better. In creating their case they cite several examples, such as Port Vell in Barcelona and London Docklands where an integrated approach to transport and development have yielded leisure dividends.

In conclusion, what lessons can be drawn for the leisure property industry? There is a need to recognise that leisure and tourism spending is essentially discretionary - whatever claims to the contrary may be made by marketing consultants. For long-term success, both developers and operators should not underestimate the need to build flexibility into schemes to accommodate shifting patterns of demand. Undoubtedly, fashions in pastime pursuits will change and government intervention is a factor that can artificially distort both the supply of the product (through the planning regime) and actions which indirectly affect demand.

A number of key challenges emerge, but the most fundamental is the need for good asset management. This includes the ability to understand the nature of leisure demand and to be able to relate leisure spending to its true competitive environment. With the rise of the global economy, this is a particularly demanding exercise.

Sarah L. Sayce August 2001

\section{References}

1. Dodona Research (2001) Cinemagoing 9, www.dodona.co.uk.

2. This point is made forcefully by Mark Buchanan in his recent book Ubiquity.

3. Kaufman, D. (2001) 'Crouching tiger or hidden dragon?', Leisure Management, Attractions Management, July/August, pp.14-17.

4. McIntosh, A. (2001) 'Planning revisited', Leisure Management, July/August, p.18. 